\title{
The Inheritance and Development of Feng Yangko of Yuanping from the Perspective of Cultural Ecology
}

\author{
Zhenghui Jia \\ College of Music, Shanxi University, Taiyuan, China \\ Email: Huier.jia@163.com
}

How to cite this paper: Jia, Z. H. (2020). The Inheritance and Development of Feng Yangko of Yuanping from the Perspective of Cultural Ecology. Open Journal of Social Sciences, 8, 198-206.

https://doi.org/10.4236/jss.2020.89014

Received: July 7, 2020

Accepted: September 21, 2020

Published: September 24, 2020

Copyright (อ 2020 by author(s) and Scientific Research Publishing Inc. This work is licensed under the Creative Commons Attribution International License (CC BY 4.0).

http://creativecommons.org/licenses/by/4.0/

\begin{abstract}
In recent years, as an important part of the local cultural ecology, Feng Yangko of Yuanping has become a serious and even declining phenomenon. In order to alleviate this endangered situation and promote its effective cultural inheritance and innovative development, under the guidance of the Measures for the Management of National Cultural Ecological Reserves and the principle of holistic protection, this paper reconstructs the path of its inheritance and development from the perspective of cultural ecology after the reflection of the current situation of Feng Yangko.
\end{abstract}

\section{Keywords}

Cultural Ecology, Feng Yangko, Inheritance, Development

\section{Introduction}

For a long time, Feng Yangko of Yuanping, as a local excellent cultural ecological card, has been popular among the public with its diverse and friendly performance forms, novel and rich costumes and props, clever and unique dance movements, and lively and cheerful music lyrics. In 2008, it was included in the first batch of national intangible cultural heritage list.

But at the time, Feng Yangko of Yuanping was critically endangered. On the one hand, with the enrichment of new forms of song and dance, the attraction of Feng Yangko of Yuanping decreased. The introduction of Western songs and dances and the prosperity of popular songs and dances make Feng Yangko of Yuanping, a rural dance with strong local flavor, obviously less attractive and unable to attract the attention of the new generation of young people. On the other hand, the passing of old artists makes it more difficult to pass on their 
skills. The number of young people who want to watch Feng Yangko continues to decline, and the next generation who are willing to inherit their skills is even more rare. With the passing of the older generation of artists, many stunts of Feng Yangko are almost extinct, the teams of actors also present a flow, scattered and unstable state. All of these are very unfavorable to the cultural inheritance and innovative development of Feng Yangko (Xinhua Net, 2018).

On December 10, 2018, the Ministerial Meeting of the Ministry of Culture and Tourism adopted the Administrative Procedures for National-level Cultural Ecological Reserves, which took effect from March 1, 2019. According to the Procedures, the term of "national cultural ecological protection areas" as mentioned in the document refers to the specific areas with the protection of intangible cultural heritage as the core and the overall protection of cultural forms with rich historical and cultural deposit, good survival status, important value and distinctive feature, and the establishment of which is approved by the Ministry of Culture and Tourism.

Guided by the Procedures, based on the principle of integrity protection, after a comprehensive investigation of the cultural ecological development of Feng Yangko of Yuanping, the author sorted out and affirmed its cultural value, and put forward multiple measures for its overall inheritance and development, in the hope of benefiting its revival.

\section{The Cultural Value of Feng Yangko of Yuanping}

\subsection{Unique Prop Culture}

Take shaking the hat with bamboo circle as an example. This novel and unique prop add a lot of personality and charm to Feng Yangko. As a companion factor of dance, the unique design of shaking the hat with bamboo circle has a great influence on the dance form and music rhythm, and indispensable to the formation of the dynamic and spiritual charm. Compared with other folk songs and dances in Shanxi province and even other parts of country, the unique characteristic of shaking the hat with bamboo circle is also very typical, with distinct difference and irreplaceability.

\subsection{Unique Composition of Lyrics}

Among Feng Yangko's lyrics, function words abound, which is rare in the folk songs and dances of Shanxi and even other parts of the country. It is worth noting that these function words do not have exact lyrics, but according to the singer's individual ability and mood to sing at the scene, which undoubtedly adds some interest and mystery to Feng Yangko. This improvisation not only tests the singer's skill and ability, but also plays an incomparable role in shaping the charm of Feng Yangko.

\subsection{Profound Folk Custom Value}

It is not accidental that Feng Yangko can be inherited and developed for hun- 
dreds of years. Instead, it is closely related to its profound folk customs and values. In Yuanping, such folk activities as "Going to yard", "Walking through the streets for a show" and "Expulsing the plague God" are very popular and willing to be participated in. In each of these folk activities, there must be some performance of Feng Yangko. It can even be said that Feng Yangko and these folk activities accompanies by the development of common prosperity. Therefore, the folk custom value of Feng Yangko is significant. Especially in the contemporary era when western culture has permeated into China and traditional folk customs are gradually declining, the folk factors of Feng Yangko are of great research and protection value. Of course, as a name card that could best reflect the folk customs of Yuanping, the effect of Feng Yangko on the local folk customs is also noteworthy. For example, some works such as Watching the Lantern and Lighting the Lantern Mountain advise people to do good from virtual aspect and not to do evil even in a small way. Congratulations on Birthday advocates filial piety. Celebrating the birth of baby in one month is a tribute to family life and good love. Selling Surplus Grain embodies the modern good life of gratitude and satisfaction (Gu et al., 2014). The dissemination of these Feng Yangko works plays a great role in the formation and cohesion of local folk customs in Yuanping. It is of great significance to the understanding of local folk customs, historical and cultural tradition. And it has important reference value for the construction of contemporary spiritual civilization.

\subsection{Profound Humanistic Value}

Feng Yangko of Yuanping has been inherited for hundreds of years since its formation in the early Qing Dynasty. It contains rich historical and cultural value. In particular, those works and characters adapted from long history legends and stories have great influence on the historical and humanistic values to our study of Yuanping. Some Feng Yangko legends, such as "Crazy Son" and "Wild Doctor" happened during the first emperor restored the border in Qin Dynasty, the peasant uprising army at Liangshanpo ambushed the place of execution in the late Northern Song Dynasty, and the upturned brim and red pompon on the caps were similar to the ones of the soldiers of the Song dynasty (Suo, 2018). The origin of these things related to Feng Yangko and its innovative development need to be studied and protected by us.

\section{Implementation of Integrated Protection of Feng Yangko from the Perspective of Cultural Ecology}

In recent years, the Municipal Party Committee and the Municipal Government in Yuanping have gradually increased their attention to Feng Yangko and continuously explore its multiple values to support its inheritance and protection. However, the situation of diminishing audience and difficult inheritance of the Feng Yangko still exist.

We cannot stand by the declination of Feng Yangko, a precious intangible 
cultural heritage. Under the guidance of the Measures for the Management of National Cultural Ecological Protection Zones and referring to the protection and development of other cultural ecological reserves, the author puts forward the following suggestions to the three major subjects of school, government and people respectively, and proposes multiple measures to promote the overall inheritance and development of the cultural ecology of Feng Yangko of Yuanping.

\subsection{The School Music Education of Feng Yangko of Yuanping Must Be Taken Seriously}

As the mainstream way of music education and inheritance, school education is an important way to inherit and develop Feng Yangko. Bringing Feng Yangko into school music education and increasing the proportion of relevant resources are important guarantee for Feng Yangko to carry forward. By setting the tone, building the curriculum, attaching great importance to collect folk songs, extending the tradition and effectively establishing the academic ecological circle, the charm of Feng Yangko of Yuanping can be enhanced, interest in folk music has increased in academia and society, so as to realize its inheritance and development.

\subsubsection{Setting the Tone}

Taking the folk music inheritance as the foundation of school music education. Nowadays, the music universities in Shanxi and even the ones around the country pay more attention to the inheritance of folk music in theory but less in practice. The music education of the school has dabbled in the excellent music culture of both ancient and modern China and foreign countries, but the status of folk music is not high among them. The basic function of music education is to preserve music culture and maintain its existence, and to provide a way for its inheritance and development (Luo, 2016). Therefore, only by recognizing the importance of folk music as the root of our music culture, putting folk music in a certain theoretical height, and taking the inheritance of folk music as the foundation of music education in schools, can we highlight our own personality and advantages in the world's outstanding music groups. In order to inherit and develop Feng Yangko of Yuanping, some theoretical work of music colleges should not be ignored. Especially for those music schools in Yuanping and even in Shanxi province, they should really realize the importance of Feng Yangko, arm music education in schools with correct thoughts and theories, and put folk music inheritance at the foundation of school music education when systematically constructing music education theories. When introducing educational resources, we should incline to folk music resources properly, to keep the life of Shanxi folk music flowing.

\subsubsection{Constructing Courses}

Strengthening the construction of Feng Yangko courses. School music education, only by adding more folk music resources into the classroom, can the 
school achieve the goal of folk music being recognized, understood, studied, and even inherited and developed. Therefore, in order to innovate and inherit Feng Yangko, the course of "Feng Yangko" must be set up in the music colleges and universities in Shanxi, especially in Yuanping, to introduce Feng Yangko and its related teaching resources into the classroom, and then present it to the students in a three-dimensional way. At the same time, in the course education of "music history", the history of Feng Yangko should also be added, so that college students can have a deeper understanding of the development history and cultural background of Feng Yangko. In other music courses, attention should be paid to guide students to combine with folk music factors such as Feng Yangko and create new musical works. Besides, students' intuitive understanding and feeling of Feng Yangko can also be increased by organizing folk music culture lectures and holding folk concerts of Yuanping, which not only highlights the school-running characteristics of local music colleges and universities, but also promotes the inheritance and development of Feng Yangko of Yuanping. It is killing two birds with one stone.

\subsubsection{Paying Attention to the on-the-Spot Collection}

Feeling the Feng Yangko in the field. Nowadays, most of the music education in colleges and universities focus on classroom education. However, folk music, a culture with a strong local character, can only be kept in its original flavor by placing it in a specific background. Therefore, the inheritance of Feng Yangko requires educators to lead students into the fields through reforming boldly, going deep into the folk, and having a deep understanding of its cultural soil and connotation (Qiu, 2019). After all, the theoretical knowledge learned in classroom education cannot be deeply understood and internalized without considering the actual situation. Music instructors set aside a certain amount of time every semester to lead students to attend gatherings and temple fairs in Yuanping to understand the folk customs and watch the live performances of Feng Yangko singers. This is a great opportunity for students to intuitively understand Feng Yangko, which enables them to have an overall perception and in-depth understanding of its style, meaning and function. In this way, the education and inheritance of Feng Yangko are organically combined. They promote each other and develop in harmony.

\subsubsection{Continuing Tradition}

Attaching importance to the inheritance of oral and mental instruction. Music education differs from general school education in that it must be expressed orally. Unfortunately, in recent years, music education in China has been greatly influenced by western educational concepts, with emphasis on theory rather than practice, and emphasis on development rather than tradition. In this context, the use of oral and mental music education is becoming less and less, which affects the educational environment for the inheritance and development of traditional folk music and is not conducive to the preservation and inheritance of 
these "living fossils". As a matter of fact, different from the simple and quantitative music typed inheritance mode of western music education, the traditional Chinese oral teaching that inspires true understanding within is more integrated with teachers' understanding of works, flexible innovation, and individual guidance and correction of students (Suo, 2019). This kind of educational inheritance mode of integrating creativity and openness can further explore the charm of music works and the diversified personality of students' works, which coincides with the quality-oriented education advocated by the current academic circle. Therefore, the inheritance and development of Feng Yangko of Yuanping could not be separated from the traditional way of oral teaching that inspires true understanding within in music education. In the actual operation of school education of Feng Yangko of Yuanping, the application of oral teaching that inspires true understanding within teaching method must be increased to ensure the original inheritance and innovative development of the works.

\subsection{The Accurate Effort of Municipal Government of Yuanping Is Also Indispensable}

For the inheritance and development of Feng Yangko of Yuanping, school education alone is not enough, it is also necessary for the government of Yuanping to pay more attention and control the overall situation, so as to lead its future development direction and path. Through establishing brand, strengthening publicity and providing more stages, the cultural ecosphere of Feng Yangko of Yuanping will be expanded, so as to effectively promote its inheritance and development.

\subsubsection{Strengthening Publicity}

Through strengthening the propaganda work of folk music such as Feng Yangko of Yuanping, a perfect protection mechanism is established. Feng Yangko, as an excellent local music culture, is a wonderful work of the people of Yuanping. However, to realize its innovation inheritance and development, it is not enough to only rely on the efforts within the plain area. The government should strengthen the coordination and publicity work, pay more attention to the propaganda of Feng Yangko in media resources, so that people inside and outside Yuanping can fully contact and understand the value and essence of Feng Yangko. For example, traditional media such as TV and newspaper and new media such as Weibo and WeChat are used to publicize and spread the Feng Yangko, so as to establish its positive image as a "living fossil" of intangible cultural heritage (Wang, 2018). In fact, many works of Feng Yangko are endowed with excellent cultural genes of the Chinese nation, such as tenacity and optimism. Under the environment of full of multiple values in China, it is very important and even necessary for Yuanping municipal government to combine the cultural attributes of Feng Yangko with core socialist values, guide people to re-reflect and accept the excellent traditional culture, enhance cultural confidence and recognition, and establish a healthy world outlook and values in the process of 
external publicity.

\subsubsection{Setting up Brand}

Building culture brand with folk music characteristic from Yuanping. It is possible to explore the establishment of excellent local music culture brand of Feng Yangko of Yuanping, infuse its higher brand cultural value, and build a unique regional cultural brand of Yuanping in an all-round and systematic way. Under this brand, personalized themed cultural activities and services are arranged and planned according to the attributes of cultural products. Under the cultural brand, the traditional Feng Yangko of Yuanping can be created by combining the local folk customs of Yuanping and utilizing the cultural elements of current pop music in fairs, festivals and grand ceremonies, or forming a cultural development company through contracting with some outstanding Feng Yangko artists, systematic packaging training, and then back to the market again, or hiring experts and scholars for recording and transmitting music, assembling into a book, burning CDs.

\subsubsection{Providing Stage}

Providing more stages for Feng Yangko of Yuanping. The traditional way of Feng Yangko is usually performed by artists on specific occasions and watched by the audience in a circle. Although to a certain extent, such face to face performance and viewing can shorten the distance between performers and viewers, but due to the limitations of the field, the range of dissemination is very limited. In the new era, the rapid development of various media can effectively make up for the shortage of venues. The use of media resources, of course, cannot be separated from the leading and deployment of local governments (Song, 2020). On the one hand, the film and television communication are accepted because of wide range audience and three-dimensional. The government can cooperate with TV stations to create a special cultural program of Feng Yangko of Yuanping, regularly launch characteristic cultural content, or add the content of Feng Yangko of Yuanping to existing cultural programs. On the other hand, the power of new media, especially We-Media, cannot be underestimated. QQ, Weibo and WeChat, as popular social networking platforms, not only improve the efficiency of communication, but also provide multiple platforms for the public to show their talents. The government should recognize and attach importance to this force, strengthen the supervision and innovative promotion of its content while it plays its role.

\section{3. "Master in the Folk", Focusing on Excavating and Cultivating the Folk Power of Feng Yangko of Yuanping}

The school and the government are duty-bound to inherit and develop Yuanping Feng Yangko. In addition, the vast folk field is the biggest stage and the strongest force for Yuanping Feng Yangko to play its role. We should pay full attention to the folk power, especially the power of folk artists, to promote the 
inheritance and development of folk music of Yuanping.

\subsubsection{Looking for Artists}

Mining excellent folk music culture source. Yuanping's folk music source must be in the folk. As an old saying goes, "The master is in the folk". Therefore, it is an indispensable work for the inheritance of folk music such as Feng Yangko of Yuanping to seek excellent artists from the folk. In fact, many folk artists from Yuanping are "living fossils" that record Feng Yangko culture in Yuanping and are important cultural resources. Since Yuanping has such a rich cultural heritage, it is necessary to make full use of it, go to grass-roots level for investigation, grasp the relevant information of Yuanping folk artists, and register their age, address, contact information and musical expertise (Zhang, 2020). In this way, in the process of inheriting and developing Yuanping Feng Yangko, we can make targeted contact with music artists with relevant expertise and seek help for the lack of cultural resources. In this way, in the process of inheriting and developing Feng Yangko, it can be said that the strength of folk artists is very important to the development of it. It is imperative to establish the database of Yangko artists and expand the inheritance team of Feng Yangko of Yuanping.

\subsubsection{Focusing on Infrastructure}

It is necessary to start from the child to carry forward Feng Yangko. On the one hand, China is full of diverse cultures in the present day. On the other hand, excellent traditional culture such as Feng Yangko is not very popular among teenagers. However, if teenagers lack the edification of excellent traditional culture, they will lack not only the love for hometown and nation, but the genetic endowment of excellent national culture. Therefore, the inheritance and development of Feng Yangko should be started from the childhood. Especially at the local place, from kindergarten and primary school, family, school and other places should build Feng Yangko study atmosphere, such as inviting some folk artists to perform for the children, or organizing the children to appreciate fair music and festival music. The excellent Feng Yangko which suitable for children can also be added into the music curriculum (Song et al., 2019). In this way, it can strengthen the children's sense of identity and pride in this excellent local culture, consciously or unconsciously complete the inheritance and development of Feng Yangko. It is well known that children are the future of the country. Children from Yuanping are the future of folk music such as Feng Yangko.

\section{Conclusion: To Create a Better Future of Feng Yangko Culture Ecosystem with Holistic Thinking}

Feng Yangko of Yuanping, due to its diversified forms, rich props, clever dance and active lyrics, must be adhered to the principle of integrity in its effective inheritance and innovative development. Only with the strong preference of government policies and schools and the continuous promotion of various folk forces, can the construction and development of the cultural ecology of Feng 
Yangko be effectively promoted, so as to promote the creative transformation and innovative development of the excellent Chinese traditional culture. It is being looked forward to the bright future of the cultural ecospheres of Feng Yangko from the three fields of school, government and folk.

\section{Conflicts of Interest}

The author declares no conflicts of interest regarding the publication of this paper.

\section{References}

Gu, X., Wang, L., \& Shi, L. (2014). Research on Feng Yangko of Yuanping. Beijing: China Wenlian Press.

Luo, L. (2016). On the Development of Music Education Based on Cultural Ecological Concept. Journal of Nanjing University of the Arts, No. 3, 51-52.

Qiu, B. (2019). Research on the Construction of Cultural Ecological Protection Zone Under the Concept of Holistic Governance-A Case Study of Jinzhong National Cultural Ecological Protection Experimental Zone. Journal of Jinzhong University, No. 2, 31-32.

Song, L., Qiao, Y., \& Feng, Y. (2019). Application of Protection and Inheritance of Folk Music in Private Colleges in Shanxi Province in the New Era. Northern Music, No. 16, 113-114.

Song, T. (2020). The Multi-Dimensional Construction of Lingnan Ballad Cultural Ecology under the Framework of Greater Bay Area. Guangdong Economy, No. 3, 79-80.

Suo, Y. (2018). Analysis on the Value of the Theoretical Basis of Yuanping Feng Yangko. Home of Drama, No. 34, 91.

Suo, Y. (2019). Research on the Inheritance and Development of Feng Yangko. Ginseng flower, No. 4, 95.

Wang, Y. (2018). A Study on the Artistic Representation and Inheritance of Feng Yangko. Contemporary Music, No. 12, 113.

Xinhua Net (2018). Measures for the Management of National Cultural Ecological Reserves.

Zhang, Y. (2020). Research on Archives Protection of Folk Music in the Information Age. Archives Management, No. 1, 87. 